\title{
Does the Mediterranean diet predict longevity in the elderly? A Swedish perspective
}

\author{
Gianluca Tognon • Elisabet Rothenberg • \\ Gabriele Eiben • Valter Sundh • Anna Winkvist • \\ Lauren Lissner
}

Received: 14 July 2010 /Accepted: 28 October 2010 /Published online: 26 November 2010

(C) The Author(s) 2010. This article is published with open access at Springerlink.com

\begin{abstract}
Dietary pattern analysis represents a useful improvement in the investigation of diet and health relationships. Particularly, the Mediterranean diet pattern has been associated with reduced mortality risk in several studies involving both younger and elderly population groups. In this research, relationships between dietary macronutrient composition, as well as the Mediterranean diet, and total mortality were assessed in 1,037 seventy-year-old subjects (540 females) information. Diet macronutrient composition was not associated with mortality, while a refined version of the modified Mediterranean diet index showed a significant inverse association $(\mathrm{HR}=0.93$, 95\% CI: 0.89 ; 0.98). As expected, inactive subjects, smokers and those with a higher waist circumference had a higher mortality, while a reduced risk characterized married and more educated people. Sensitivity analyses (which confirmed our results) consisted of: exclusion of one food group at a time in the Mediterranean diet index, exclusion of early deaths,
\end{abstract}

G. Tognon $(\bowtie) \cdot$ G. Eiben $\cdot$ V. Sundh $\cdot$ L. Lissner

Public Health Epidemiology Unit,

Department of Public Health and Community Medicine,

University of Gothenburg, Sahlgrenska Academy,

Box 454, 40530 Göteborg, Sweden

e-mail: gianluca.tognon@gu.se

E. Rothenberg $\cdot$ A. Winkvist

Department of Clinical Nutrition,

University of Gothenburg, Sahlgrenska Academy,

Box 459, 40530 Göteborg, Sweden censoring at fixed follow-up time, adjusting for activities of daily living and main cardiovascular risk factors including weight/waist circumference changes at follow up. In conclusion, we can reasonably state that a higher adherence to a Mediterranean diet pattern, especially by consuming wholegrain cereals, foods rich in polyunsaturated fatty acids, and a limited amount of alcohol, predicts increased longevity in the elderly.

Keywords Elderly · Mediterranean diet - Diet quality . Macronutrient intake $\cdot$ Diet adherence $\cdot$ Mortality

\section{Introduction}

Epidemiologic studies indicate that quality of diet together with other lifestyle factors have considerable influence on health status as well as mortality risk (Huijbregts et al. 1997; Seymour et al. 2003; Haveman-Nies et al. 2003). Although many studies have examined effects of single nutrients, foods, or food groups on health status, it is becoming increasingly evident that the assessment of dietary patterns could be a practical alternative in the study of diet and health associations (Mai et al. 2005). Among other a priori patterns (such as the Healthy Eating Index or the Recommended Food Score), the Mediterranean diet has already been shown to possess many beneficial effects, as first became evident years ago in the SevenCountry Study (Keys 1980). This diet is characterized 
by a high intake of vegetables, legumes, fruits, nuts and seeds, cereals (that in the past were largely unrefined), and a high intake of olive oil combined with a low intake of saturated lipids, a moderately high intake of fish (depending on the proximity of the sea), a low-to-moderate intake of dairy products (and then mostly in the form of cheese and yogurt), a low intake of meat and meat products as well as a regular but moderate intake of ethanol, primarily in the form of wine and generally during meals (Willett et al. 1995).

The Mediterranean diet was first considered a dietary pattern that protected against coronary heart disease (de Lorgeril et al. 1999). This was confirmed very recently by a longitudinal study showing that Mediterranean diet is associated with a higher preservation of ventricular function and a more favorable prognosis after an acute coronary event (Chrysohoou et al. 2010). However, in previous studies, other beneficial effects on total mortality have been discovered (Trichopoulou et al. 2005). Interestingly, a recent paper on the Swedish population showed a reduction in total mortality among young women (Lagiou et al. 2006). In addition, a Mediterranean dietary pattern has also been shown to increase longevity among European elderly of the Healthy Aging: a Longitudinal study in Europe (HALE) project (Knoops et al. 2004).

In the present study, we investigated the association of the Mediterranean diet pattern with total mortality in a population of Swedish 70 year olds.

\section{Subjects and methods}

Subjects, dietary assessment, and outcome definition

This study is based on the Gerontological and Geriatric Population Studies in Gothenburg (H70; Eiben et al. 2004, 2005; Rothenberg et al. 1996, 1997 , 1998). The Revenue Office of Gothenburg has a registry of all inhabitants, from which representative study groups of specific ages may be identified. Using this registry, population-based samples of 70-year-old residents were recruited for health examinations in 1971, 1981, 1992, and 2000. In the first two examinations, 70-year-old cohorts born in 1901 and 1911 were sampled and invited to participate based on date of birth. In the latter two examinations, men born in 1922 and 1930 were sampled in the same way, while the 70-year-old women born in those years were identified on the basis of previous inclusion in the Prospective Population Study of Women in Gothenburg (PPSW, Bengtsson et al. 1997; Lissner et al. 2003). Response rate decreased from $84 \%$ and $86 \%$ for men and women, respectively, in the earliest birth cohort to $65 \%$ for both sexes in the most recent cohort. Overall, a total of 1,277 men and women still residing in the Gothenburg district had undergone diet history examinations at the age of 70 (Eiben et al. 2004, 2005). Diet history was validated by comparison of energy intake (EI) with estimated total energy expenditure (TEE) by heart rate monitoring, activity diary, and doubly-labeled water (Rothenberg et al. 1998).

In order to exclude implausible dietary intakes, subjects in the highest and lowest 5 percentiles of the ratio between energy intake and calculated basal metabolic rate (BMR) were not included in the present analyses $(N=149)$. BMR was predicted from weight (W) by means of standard equations for subjects aged 60-74 (males: $0.0499 \times \mathrm{W}+2.93$; females: $0.0386 \times W+2.875$; Department of Health 1991). Other exclusions included cases missing information on diet or on potential confounders $(N=91)$. The final study sample included 1,037 subjects $(52.1 \%$ females $)$. All cohorts have been monitored continuously for mortality by linking personal identification numbers with the national death registration system. The most recent mortality follow-up was in 2009. In a sub-sample of 781 subjects, a follow up at 75 years for both weight and waist circumference was available. In supplementary analyses, observation time was truncated to 8.5 years to give all cohorts equal follow-up time when estimating survival probabilities.

Definitions of food groups and of the Mediterranean diet scores

To assess the association of diet and lifestyle factors with total mortality, a refined version of the modified Mediterranean diet score (refined mMDS) was calculated, based on existing knowledge from the scientific literature on positive effects of wholegrain cereals (Flight and Clifton 2006) and moderate alcohol intake (Mukamal et al. 2010) as well as on the fact that polyunsaturated fats (PUFA) and not only monounsaturated fats (MUFA) are the principal unsaturated fats in non-Mediterranean diets (De Lorgeril et al. 
1994). The score comprised nine components: (1) vegetables and potatoes, (2) legumes, nuts, and seeds, (3) fruit and fresh juices, (4) wholegrain cereals, (5) fish and fish products, (6) ratio of MUFA+PUFA to saturated fats (SAFA), (7) alcohol intake, (8) meat, meat products, and eggs, (9) dairy products. Intake of each component was adjusted to daily energy intakes of 2,500 kcal (10.5 MJ) for men and 2,000 kcal (8.5 MJ) for women. Although these values are not considered as recommended daily energy intake for both genders, they were chosen based on previous research on this subject (Knoops et al. 2004) and used to obtain energy adjusted associations in all the analyses. The sex-specific median intakes were taken as cut-off points. In any case, the final score is considered a measure of relative adherence to the Mediterranean diet pattern. The diet score varied from 0 (low-quality diet) to 9 (high quality diet). For each of the nine components, except for meat and dairy products, a value of 1 was assigned to subjects whose consumption was higher than the sex-specific median, and 0 to the others. For meat and dairy products, the reverse rule was applied. An alternative version of this score, previously used in the HALE project (HALE mMDS, Knoops et al. 2004) was also produced, including only MUFA in the numerator of the fat ratio, total instead of wholegrain cereals, and excluding alcohol intake from the score.

\section{Statistical analyses}

Cox proportional hazards models were used to estimate the effects of diet, smoking status, education, physical activity, and other potential confounders on total mortality, to November 2009. All the models used in this study were adjusted for potential confounders such as sex, baseline body mass index (BMI), waist circumference, smoking status, physical activity level, marital status, education, and birth cohort.

Analyses of macronutrients and mortality were first performed by means of the standard multivariate model (Willett 1998), in which each macronutrient was tested separately, with or without adjustment for energy intake. Further analyses were conducted by means of the multivariate nutrient density model (Willett 1998), in which the nutrient densities (percentages of energy from non-alcohol sources in a scale of 5\% units) from total fat and protein intakes are included as independent variables. The model thus estimates the effect on the outcome of the iso-energetic replacement of 5\% of energy provided by the reference macronutrient (the one not included in the model, e.g., carbohydrates) with a similar amount of calories provided by all the other macronutrients included in the model (e.g., proteins and fats). In these analyses, alcohol intake was added separately on a $\mathrm{g} /$ day basis.

Next, analyses were performed both on the Mediterranean diet scores (HALE and refined MMDS) on a continuous scale as well as on scores of 6-9 in refined mMDS or 5-8 in HALE mMDS in comparison with the others. In order to examine if the estimates for mortality were influenced by any of the covariates, or if any of these could remove part of the effect, the crude hazard ratios (HRs) for the dietary and lifestyle factors were also calculated and compared with the adjusted HRs. Finally, the mortality risk was also estimated in single food groups contributing to these scores. Food intakes were re-scaled according to medians, as done for the score calculations. For illustration, the doseresponse effect of the mortality risk in subjects with growing levels of refined mMDS compared to the risk in subjects characterized by a score $\leq 1$ was investigated.

In addition, a series of sensitivity analyses were performed, the most critical of which was the estimation of the association between mortality risk and different versions of the refined mMDS, calculated by excluding, one at a time, each component of the score in order to determine that the effect was not driven by a single food group. Other sensitivity analyses included adjusting for cardiovascular risk factors such as weight and waist circumference change, baseline blood pressure, fasting glucose, total cholesterol, and triglycerides or for activities of daily living variable (ADL, based on need of help for everyday activities). The activities of daily living variable was based on the Katz index, which is similar to the Barthel Index, and hence based on the need of help for at least one out of nine different activities, including house cleaning, shopping, transport, cooking, washing, dressing, using the toilet, ambulation, and feeding (Sonn and Asberg 1991). Furthermore, analyses were repeated after excluding the first 2 years of total mortality follow-up.

We also repeated the Cox analysis on the refined mMDS, by censoring at a fixed follow-up duration of 8.5 years (approximately the longest follow-up time in the latest-born cohort) instead of censoring at a fixed date. Crude proportions of subjects still alive at 8.5 years were also calculated according to three 
different levels of the score $(\leq 3,4-6, \geq 7)$ and the association between adherence to the Mediterranean diet pattern and survival was assessed by means of a chi-square test.

Finally, potential confounders (see above) were examined in more detail, including an estimation of the mortality HRs in subjects characterized by a score in the highest four levels ( $>4$ for the HALE mMDS, $>5$ for the refined mMDS) compared to the other subjects. Moreover, the assessment of the effect of all main covariates on mortality included in the previous models was also performed.

All statistical analyses were considered significant under a $p$ value of 0.05 and were carried out using the SAS statistical software version 9.2 (SAS Institute, Cary, NC, USA).

\section{Bioethics}

The latest $\mathrm{H} 70$ examinations (since 1992) have been approved by the Gothenburg University Ethics Committee in accordance with the Declaration of Helsinki (1989) of the World Medical Association. All participants were informed of the aims and procedures of the study and gave their consent.

\section{Results}

Descriptive analyses

Main descriptive analyses are reported in Tables 1 (dietary variables), 2 (Mediterranean diet scores), and 3 (potential confounders and other cohort descriptors). Dietary intake distributions across the birth cohorts have previously been described (Eiben et al. 2004; Rothenberg et al. 1996). Table 1 shows that, according to trend test, across the four birth cohorts there was an increase in the consumption of vegetables and potatoes, fruit, legumes plus nuts and seeds, fish and fish products, meat and meat products, red wine and alcohol. In contrast, a decrease in the consumption of cereals (both total and wholegrain) was observed. No clear patterns emerged for dairy products, MUFA/ SAFA ratio and (MUFA+PUFA)/SAFA ratio. Regarding macronutrient intakes, a trend in protein, carbohydrate, and fat intake was observed. Energy intakes showed a slight tendency to an increase across the cohorts, and the ratio between energy intake and BMR was consistently high (1.5 \pm 0.3$)$, indicating a good quality of nutritional data. In the subjects excluded for implausible dietary intakes (highest and lowest 5 percentiles of energy intake vs. basal metabolic rate ratio), EI/BMR was either less than 0.9 or greater than 2.2 (data not shown).

Regarding the two scores measuring the adherence to the Mediterranean diet (Table 2), no major differences appeared from cohort to cohort, although for the refined mMDS a slight but significant increase was evident (4.3 \pm 1.6 in 1901 cohort to $4.8 \pm 1.8$ in 1930 cohort), probably due to the increase in wholegrain, alcohol, and PUFA intakes included in this score and not in the HALE mMDS.

Table 3 shows the descriptive analyses of potential confounders. Both genders were equally represented in the population $(47.9 \%$ men). Subjects characterized by a BMI $<20$ were only a minority (3.1\%), while obese subjects constituted $15.8 \%$ of the total population. A high waist circumference $(>88 \mathrm{~cm}$ in women, $>102 \mathrm{~cm}$ in men), characterized $31.0 \%$ of the subjects. Only $14.2 \%$ of subjects were physically inactive, $62.1 \%$ were married, and more than $30 \%$ of subjects were smokers (or stopped less than 10 years ago) or had an education above basic (i.e., 6 years of schooling or more). Overall, in the studied population, there were 630 deaths $(60.8 \%)$ until November 2009: 309 women and 321 men.

Regarding main cardiovascular risk factors depicted in Table 3, which include variations in anthropometry over 5 years, we observed a decrease in mean weight from $74.2 \mathrm{~kg} \pm 12.9$ at baseline to $72.3 \mathrm{~kg} \pm 13.2$ at follow up (mean change: $-1.9 \mathrm{~kg} \pm 5.4$ ), a quite stable waist circumference (mean change: $-0.2 \mathrm{~cm} \pm 7.4$ ) and BMI (mean change: $-0.3 \mathrm{~kg} / \mathrm{m}^{2} \pm 1.9$ ). Diastolic blood pressure means were less than $90 \mathrm{mmHg}(87.4 \mathrm{mmHg} \pm$ 11.9), while systolic blood pressure mean was above $140 \mathrm{mmHg}$ (159.0 mmHg \pm 23.6$)$. Regarding plasma parameters (only available at baseline), fasting glucose was equal to $100.8 \mathrm{mg} / \mathrm{dL} \pm 36.0$, total cholesterol was $233.3 \mathrm{mg} / \mathrm{dL} \pm 77.8$ while triglycerides was $132.4 \mathrm{mg} / \mathrm{dL} \pm 70.6$.

Diet quality and mortality

In the present cohort, the total mortality was around $60 \%$, with a higher rate in the earlier born cohorts and a lower in the later born cohorts $(100 \%$ in $1901,98 \%$ in $1911,48 \%$ in 1922 , and $15 \%$ in 1930 birth cohort). 
Table 1 Means and standard deviation in comparison with medians and 95\% Confidence Limits (CLs) of dietary variables used in the analyses, including test for trend across the birth cohorts

\begin{tabular}{|c|c|c|c|}
\hline Food groups/macronutrients & Overall mean $(N=1,037)$ & Median intakes and $95 \% \mathrm{CLs}$ & $p$ for trend across birth cohorts $\mathrm{e}^{\mathrm{e}, \mathrm{f}}$ \\
\hline Vegetables and potatoes $(\mathrm{g} / \text { day })^{\mathrm{a}, \mathrm{b}}$ & $237.6 \pm 98.7$ & $\begin{array}{l}\text { o: } 209.5(99.6 ; 406.3) \\
o: 239.0(120.1 ; 432.2)\end{array}$ & $<0.0001$ \\
\hline Fruit $(\mathrm{g} / \text { day })^{\mathrm{a}, \mathrm{b}}$ & $196.6 \pm 146.3$ & $\begin{array}{l}\text { o: } 176.4(22.3 ; 527.7) \\
\text { đ: } 155.5(14.0 ; 456.0)\end{array}$ & $<0.0001$ \\
\hline Legumes nuts and seeds $(\mathrm{g} / \text { day })^{\mathrm{a}, \mathrm{b}}$ & $15.2 \pm 20.2$ & $\begin{array}{r}\text { }: 2.0(0 ; 40.0) \\
\delta^{\top}: 13.3(0 ; 60.0)\end{array}$ & $<0.0001$ \\
\hline Cereals $(\mathrm{g} / \text { day })^{\mathrm{a}}$ & $207.4 \pm 104.0$ & $\begin{array}{l}\text { o: } 165.0(68.2 ; 383.0) \\
\text { o: } 213.0(98.3 ; 442.1)\end{array}$ & $(-)<0.0001$ \\
\hline Wholegrain cereals $(\mathrm{g} / \text { day })^{\mathrm{b}}$ & $107.9 \pm 95.6$ & $\begin{array}{l}\text { q: } 74.2(0 ; 298.5) \\
\text { ภ: } 92.8(0 ; 322.0)\end{array}$ & $(-)<0.0001$ \\
\hline Fish and fish products $(\mathrm{g} / \text { day })^{\mathrm{a}, \mathrm{b}}$ & $53.8 \pm 35.8$ & $\begin{array}{l}\text { o: } 45.2(12.8 ; 105.3) \\
\delta: 53.7(13.8 ; 129.5)\end{array}$ & $<0.0001$ \\
\hline Dairy products $(\mathrm{g} / \text { day })^{\mathrm{a}, \mathrm{b}}$ & $445.1 \pm 251.7$ & $\begin{array}{l}\text { of: } 373.3(127.9 ; 829.5) \\
\text { o: } \\
446.0(74.0 ; 1061.9)\end{array}$ & 0.41 \\
\hline Meat and meat products $(\mathrm{g} / \text { day })^{\mathrm{a}}$ & $105.4 \pm 47.9$ & $\begin{array}{c}\text { ㅇ: } 89.7(38.4 ; 168.8) \\
\delta^{+}: 109.1(52.5 ; 204.9)\end{array}$ & $<0.0001$ \\
\hline Meat, meat products, eggs (g/day) ${ }^{\mathrm{b}}$ & $129.5 \pm 55.3$ & $\begin{array}{l}\text { o: } 110.1(47.9 ; 187.3) \\
\sigma^{T}: 137.7(66.3 ; 251.1)\end{array}$ & $<0.001$ \\
\hline Red wine $(g / \text { day })^{c}$ & $2.0 \pm 4.7$ & $\begin{array}{l}\text { ․: } 0(0 ; 9.8) \\
\text { ऽ: } 0(0 ; 10.7)\end{array}$ & $<0.001$ \\
\hline Alcohol (g/day) ${ }^{\mathrm{b}}$ & $6.0 \pm 9.1$ & $\begin{array}{l}\text { o: } 1.3(0 ; 13.9) \\
\text { స: } 5.3(0 ; 28.5)\end{array}$ & $<0.0001$ \\
\hline Carbohydrate $(\mathrm{g} / \text { day })^{\mathrm{d}}$ & $249.1 \pm 64.8$ & $\begin{array}{l}\text { o: } \\
\text { o: } 217.1(143.5 ; 316.8) \\
272.4(192.8 ; 398.2)\end{array}$ & 0.01 \\
\hline Protein $(g / \text { day })^{d}$ & $80.1 \pm 20.0$ & $\begin{array}{l}\text { o: } 71.2(48.6 ; 100.4) \\
+ \text { ô } \\
85.2(58.3 ; 129.0)\end{array}$ & $<0.0001$ \\
\hline Fat $(\mathrm{g} / \text { day })^{\mathrm{d}}$ & $86.1 \pm 25.4$ & $\begin{array}{l}\text { o. } 74.6(46.6 ; 110 .) \\
\text { J: } 93.5(60.1 ; 146.5)\end{array}$ & $<0.0001$ \\
\hline MUFA/SAFA ${ }^{\mathrm{a}}$ & $0.8 \pm 0.2$ & $\begin{array}{l}\text { ot: } 0.8(0.6 ; 1.1) \\
\text { స̂: } 0.8(0.6 ; 1.1)\end{array}$ & 0.40 \\
\hline$(\mathrm{MUFA}+\mathrm{PUFA}) / \mathrm{SAFA}^{\mathrm{b}}$ & $1.2 \pm 0.3$ & $\begin{array}{l}\text { o: } 1.1(0.8 ; 1.6) \\
\text { o: } 1.1(0.7 ; 1.7)\end{array}$ & 0.50 \\
\hline Energy intake (100 kcal) & $21.4 \pm 5.0$ & $\begin{array}{l}\text { o: } 18.5(13.3 ; 25.4) \\
\text { J: } 23.6(17.7 ; 33.6)\end{array}$ & 0.04 \\
\hline Energy/BMR ${ }^{\mathrm{d}}$ & $1.5 \pm 0.3$ & $\begin{array}{l}\text { o: } 1.4(1.0 ; 1.9) \\
\text { ఫొ: } 1.4(1.1 ; 2.1)\end{array}$ & 0.30 \\
\hline
\end{tabular}

\footnotetext{
${ }^{a}$ Included in HALE mMDS

${ }^{\mathrm{b}}$ Included in refined mMDS

${ }^{\mathrm{c}}$ Included in place of alcohol in an additional analysis

${ }^{\mathrm{d}}$ Not included in any scores, just included for descriptive purposes

${ }^{\mathrm{e}}$ Birth-cohort effect from a regression model adjusted for gender, BMI, waist circumference, physical activity, smoking status, marital status and education

${ }^{\mathrm{f}}$ All significant trends positive in direction except if indicated with $(-)$
}

In the first part of the present work, we analyzed the association between diet macronutrient composition and total mortality. No clear association emerged either when analyzing protein, fat, and carbohydrate intake (adjusted or unadjusted for energy intake) in standard multivariate models. Alcohol was also not associated on a continuous scale with total survival time (Table 4). Similar results were obtained when 
Table 2 General descriptive of Mediterranean diet score distributions, both stratified by birth cohort and for the overall population

\begin{tabular}{lllllll}
\hline Mediterranean diet score & $1901(N=323)$ & $1911(N=214)$ & $1922(N=88)$ & $1930(N=412)$ & Overall $(N=1,037) \begin{array}{c}p \text { for trend across } \\
\text { birth } \text { cohorts }^{\mathrm{a}}\end{array}$ \\
\hline Refined mMDS (mean $\pm \mathrm{SD})$ & $4.3 \pm 1.6$ & $4.0 \pm 1.6$ & $4.8 \pm 1.5$ & $4.8 \pm 1.8$ & $4.5 \pm 1.7$ & $<0.001$ \\
Medians (5th;95th perc) & $4(2 ; 7)$ & $4(1 ; 7)$ & $5(2 ; 7)$ & $5(2 ; 8)$ & $4(2 ; 7)$ & 0.02 \\
HALE mMDS (mean $\pm \mathrm{SD})$ & $4.1 \pm 1.5$ & $3.6 \pm 1.4$ & $4.1 \pm 1.4$ & $4.1 \pm 1.6$ & $4.0 \pm 1.5$ & $4(2 ; 6)$ \\
Medians (5th;95th perc) & $4(2 ; 6)$ & $4(1 ; 6)$ & $4(2 ; 6)$ & $4(1 ; 7)$ & 4.6
\end{tabular}

${ }^{\mathrm{a}}$ Birth-cohort effect from a regression model adjusted for gender, BMI, waist circumference, physical activity, smoking status, marital status, and education

employing the nutrient density model to describe the effect of the reciprocal substitution of $5 \%$ of energy intake from each macronutrient with carbohydrates (Table 4).

Table 3 Main covariate frequencies and cohort description

\begin{tabular}{ll}
\hline Potential confounders & Frequency $(\%)$ \\
\hline Total sample $(N=1,037)$ & 47.9 \\
Male gender & 3.1 \\
BMI $<20$ & 15.8 \\
BMI $>30$ & 31.0 \\
High waist circumference & 14.2 \\
Low physical activity at 70 & 62.1 \\
Married at age 70 & 30.6 \\
Smoker/stopped $<10$ years ago & 30.5 \\
School education above basic & 12.7 \\
Activities of daily living (ADL) & \\
& Means \pm SD \\
Additional covariates & $87.4 \pm 11.9$ \\
Baseline diastolic blood pressure $(\mathrm{mmHg})$ & $159.0 \pm 23.6$ \\
Baseline systolic blood pressure $(\mathrm{mmHg})$ & $100.8 \pm 36.0$ \\
Baseline fasting glucose (mg/dL) & $233.3 \pm 77.8$ \\
Baseline total cholesterol (mg/dL) & $132.4 \pm 70.6$ \\
Baseline triglycerides (mg/dL) &
\end{tabular}

Subsample with follow up at 75 years $(N=781)$

Changes in anthropometry

Means \pm SD

Weight change $(\mathrm{kg})$

$-1.9 \pm 5.4$

Baseline

$74.2 \pm 12.9$

Follow up

$72.3 \pm 13.2$

Waist circ. change $(\mathrm{cm})$

Baseline

$-0.2 \pm 7.4$

Follow up

BMI change $\left(\mathrm{kg} /\right.$ height $\left.^{2}\right)$

$90.0 \pm 11.4$

$90.0 \pm 11.8$

$-0.3 \pm 1.9$

Baseline

$26.4 \pm 3.9$

Follow up

$26.1 \pm 4.1$
In light of the null results obtained by the analyses of macronutrients, we then focused on the identification of a possible dietary pattern, which could be related to total mortality. In particular, we chose to study the Mediterranean diet pattern by means of a refined version of the modified Mediterranean Diet Score (refined mMDS), which we consider to reflect a closer adherence to the classic Mediterranean diet pattern.

Table 5 shows the association of refined mMDS, in comparison to the previously used HALE mMDS (Knoops et al. 2004) with mortality risk, as well as the same outcome for those food groups on whose intakes the adherence to Mediterranean diet pattern was assessed.

Regarding Mediterranean diet score, an inverse association with total mortality was shown for the continuous refined mMDS ( $\mathrm{HR}=0.93,95 \% \mathrm{CI}$ : 0.89 ; 0.98 ), while no significant association emerged with HALE mMDS, although the trend was toward an inverse association $(\mathrm{HR}=0.97,95 \% \mathrm{CI}: 0.92 ; 1.02)$. Moreover, the comparison of the lowest-risk group

Table 4 Hazard ratios and 95\% confidence limits from a Coxproportional hazard model (adjusted for gender, baseline BMI, waist circumference, physical activity, marital status, smoking status, birth cohort, and education) estimating the association of macronutrient with mortality risk and different substitution of energy from each macronutrient with the same amount of energy of another one

\begin{tabular}{lll}
\hline Macronutrient $(10 \mathrm{~g})$ & HR & $95 \%$ CLs \\
\hline Alcohol & 0.98 & $0.86 ; 1.11$ \\
Protein & 0.97 & $0.90 ; 1.04$ \\
CHO & 1.00 & $0.98 ; 1.03$ \\
Fat & 1.00 & $0.94 ; 1.07$ \\
From CHO to protein 5\% energy & 0.95 & $0.80 ; 1.14$ \\
From CHO to fat 5\% energy & 1.01 & $0.94 ; 1.09$
\end{tabular}


Table 5 Hazard ratios and 95\% confidence limits from a Coxproportional hazard model (adjusted for gender, baseline BMI, waist circumference, physical activity, marital status, smoking status, birth cohort, and education) estimating the association of both HALE and refined mMDS with mortality risk

\begin{tabular}{lll}
\hline Mediterranean diet score or food group & HR & 95\% CLs \\
\hline Refined mMDS & 0.93 & $0.89 ; 0.98$ \\
$\quad$ Crude estimate & 0.92 & $0.88 ; 0.97$ \\
Highest 4 levels vs. the others & 0.82 & $0.67 ; 0.99$ \\
$\quad$ Crude estimate & 0.81 & $0.67 ; 0.99$ \\
HALE mMDS & 0.97 & $0.92 ; 1.02$ \\
Crude estimate & 0.97 & $0.92 ; 1.03$ \\
Highest 4 levels vs. the others & 0.94 & $0.79 ; 1.11$ \\
$\quad$ Crude estimate & 0.94 & $0.80 ; 1.11$ \\
High intake/level of: & & \\
Vegetables and potatoes & 1.06 & $0.90 ; 1.24$ \\
Fruit & 1.03 & $0.87 ; 1.21$ \\
Legumes, nuts, and seeds & 0.98 & $0.83 ; 1.16$ \\
Cereals & 1.01 & $0.86 ; 1.19$ \\
Wholegrain cereals & 0.85 & $0.73 ; 1.00$ \\
Fish & 0.96 & $0.82 ; 1.13$ \\
Alcohol & 0.77 & $0.61 ; 0.97$ \\
MUFA/SAFA ratio & 0.98 & $0.84 ; 1.15$ \\
(MUFA+PUFA)/SAFA ratio & 0.96 & $0.82 ; 1.13$ \\
Low intake of: & & \\
Dairy products & 0.82 & $0.70 ; 0.96$ \\
Meat and meat products & 0.89 & $0.76 ; 1.05$ \\
Meat, meat products and eggs & $0.71 ; 0.98$ \\
\hline & &
\end{tabular}

(highest four levels of the score) versus the other subjects showed a significant inverse association for the refined mMDS (HR $=0.82,95 \%$ CI: $0.67 ; 0.99)$, but not for the highest levels of the HALE mMDS (HR= 0.94, 95\% CI: 0.79; 1.11; Table 5). Crude estimates were also calculated and, as shown in the table, they are quite overlapping with the adjusted ones, thus showing that covariates did not have any strong influence on results. The protective effect of the Mediterranean diet pattern was stronger in the two youngest birth cohorts compared to the others (data not shown).

When studying the effect of single food groups, an inverse association with total mortality was shown for high intakes of wholegrain cereals $(\mathrm{HR}=0.85,95 \%$ CI: $0.73 ; 1.00)$, alcohol consumption $(\mathrm{HR}=0.77,95 \%$ CI: $0.61 ; 0.97)$ and low intake of dairy products $(\mathrm{HR}=$ $0.82,95 \%$ CI: $0.70 ; 0.96)$ as well as low intakes of meat, meat products, and eggs $(\mathrm{HR}=0.84,95 \% \mathrm{CI}$ :
$0.71 ; 0.98)$. In contrast, other food groups were not significantly associated with mortality, such as vegetables and potatoes (HR $=1.06,95 \% \mathrm{CI}: 0.90 ; 1.24)$, fruit $(\mathrm{HR}=1.03,95 \% \mathrm{CI}: 0.87 ; 1.21)$, legumes plus nuts and seeds $(\mathrm{HR}=0.98,95 \% \mathrm{CI}: 0.83 ; 1.16)$, and fish $(\mathrm{HR}=0.96,95 \% \mathrm{CI}: 0.82 ; 1.13)$. No association was shown for either of the fat ratios (MUFA/SAFA ratio: $\mathrm{HR}=0.98,95 \% \mathrm{CI}: 0.84: 1.15$; (MUFA+PUFA) SAFA ratio: $\mathrm{HR}=0.96,95 \% \mathrm{CI}: 0.82 ; 1.13)$. It is worth mentioning that vegetables alone and potatoes alone did not show any association with total mortality (data not shown).

In Fig. 1 dose-response analysis results are depicted. Briefly, the group characterized by a refined mMDS equal to 0 or 1 was the reference, compared to the other groups with increasing levels of the score. Although none of the single comparisons reached statistical significance, the analysis showed a doseresponse tendency, thus suggesting a decrease in the mortality risk as long as the adherence to the Mediterranean diet pattern increased.

\section{Supplementary analyses}

A sensitivity analysis was performed on the refined mMDS, with the aim of understanding whether any one of the food group items included in the score could invalidate the effect of the entire score, with respect to mortality. Nine different scores were then produced, each excluding one item at a time (and keeping all others). Table 6 clearly demonstrates that the association of the refined mMDS with mortality is robust and survives all the item-by-item exclusions.

Furthermore, in order to test whether the positive effect of alcohol intake within the score could be obtained considering red wine (instead of total alcohol intake from all alcoholic beverages), considered a more accurate indicator of the Mediterranean alcoholic drinks, we ran an additional analysis, ending up with a similar outcome and a slightly stronger hazard ratio (HR: 0.92, 95\% CI: 0.87; 0.97; Table 6).

In order to confirm that the effect of diet on mortality was independent of the subjects' functional capacity levels, and thus that the effect of Mediterranean diet was not entirely explained by how impaired the subjects were at the time of diet assessment we also repeated all the models adjusting for activities of daily living variable and found no substantial change in results. Similar analyses were performed adjusting for 
Fig. 1 Dose-response analyses based on Coxproportional hazard model (adjusted for gender, baseline BMI, waist circumference, physical activity, marital status, smoking status, birth cohort and education) comparing mortality risk in subjects characterized by a refined mMDS $\leq 1$ with the same risk in subjects in the other score categories. Dots and vertical lines indicate HR and $95 \%$ confidence limits

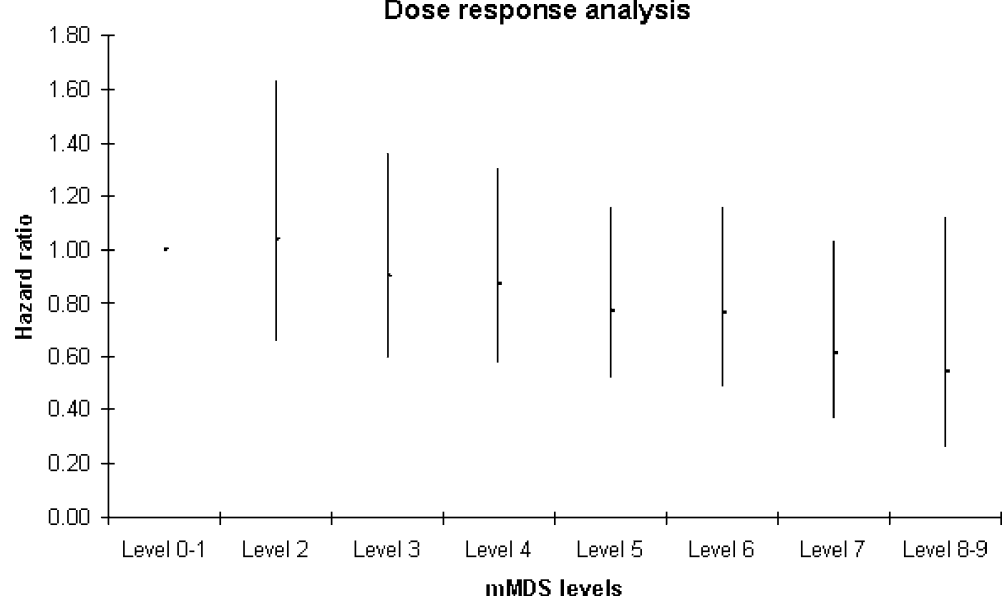

other cardiovascular risk factors, i.e., baseline blood pressure, fasting glucose, total cholesterol, and triglycerides; this did not strongly affect the results, except that the association of the dichotomous score (higher vs. lower) was attenuated ( $\mathrm{HR}=0.85,95 \% \mathrm{CI}$ : $0.70 ; 1.04)$. Adjustment for weight or waist circumference change did not substantially affect the association of the refined mMDS with mortality. However, both were inversely associated with total mortality (weight change: $\mathrm{HR}=$ 0.95, 95\% CI: 0.93; 0.97; waist circumference change: $\mathrm{HR}=0.98,95 \% \mathrm{CI}: 0.97 ; 1.00$ ), suggesting a greater mortality risk in association with weight loss. Further-

Table 6 Hazard ratios and 95\% confidence limits from a Coxproportional hazard model-based sensitivity analysis estimating the effect of the exclusion of each level of the refined mMDS+ alcohol on mortality risk (adjusted for gender, baseline BMI, waist circumference, physical activity, marital status, smoking status, birth cohort, and education)

\begin{tabular}{lll}
\hline Mediterranean diet score & HR & $95 \%$ CLs \\
\hline Refined mMDS & 0.93 & $0.89 ; 0.98$ \\
Without fat ratio & 0.92 & $0.87 ; 0.97$ \\
Without vegetables and potatoes & 0.91 & $0.87 ; 0.96$ \\
Without fruit & 0.92 & $0.87 ; 0.97$ \\
Without legumes, nuts and seeds & 0.93 & $0.88 ; 0.97$ \\
Without cereals & 0.94 & $0.89 ; 0.99$ \\
Without fish & 0.92 & $0.87 ; 0.97$ \\
$\quad$ Without dairy & 0.94 & $0.89 ; 0.99$ \\
$\quad$ Without meat & 0.94 & $0.90 ; 0.99$ \\
$\quad$ Without alcohol & 0.94 & $0.89 ; 0.99$ \\
Refined mMDS (including red wine & 0.92 & $0.87 ; 0.97$ \\
instead of alcohol) & &
\end{tabular}

more, to minimize the possibility that diet or lifestyle factors had changed in response to subclinical diseases, all analyses were also repeated after exclusion of the subjects who had died in the first 2 years of follow up. Here again, no clear difference emerged, thus confirming our main results.

Finally, the association of the refined mMDS with total mortality was also tested in a Cox model in which subject censoring was done at a fixed follow up time $(8.5$ years, the maximum in the youngest birth cohort) instead at a fixed date. The previous results were confirmed although somewhat attenuated (HR= 0.92, 95\% CI: $0.86 ; 1.00)$. The distribution of crude proportions of survival rates at 8.5 years, stratified by increasing levels of the refined mMDS were as follows: $67 \%$ survival among those characterized by a score $\leq 3,77 \%$ survival at intermediate levels of the score (from 4 to 6 ) and $80 \%$ survival among the subjects with a score $\geq 7(p=0.02)$.

Effect modification and covariates associated with diet and mortality

In order to identify potential effect modifiers, statistical interactions between all dietary and potential confounders were tested, but none of them were statistically significant at a 0.05 level. The association of the highest levels of the refined mMDS with each of the above-mentioned confounders was also investigated (Table 7). Subjects ranked to the highest levels of the score were less likely to be inactive $(\mathrm{OR}=0.42$; $95 \%$ CI: $0.25 ; 0.71)$ and more likely to be married $(\mathrm{OR}=1.47,95 \%$ CI: $1.07 ; 2.01)$, more educated $(\mathrm{OR}=1.38,95 \% \mathrm{CI}: 1.02 ; 1.86)$ or born within the 
Table 7 Hazard ratios and 95\% confidence limits from a Cox-proportional hazard model estimating the association of potential confounders included in the final model and mortality risk in the whole studied population $(N=1,037)$

\begin{tabular}{|c|c|c|c|c|}
\hline \multirow[t]{2}{*}{ Confounders } & \multicolumn{2}{|c|}{$\begin{array}{l}\text { Association with highest } \\
\text { levels of refined mMDS }\end{array}$} & \multicolumn{2}{|c|}{$\begin{array}{l}\text { Association with } \\
\text { mortality }\end{array}$} \\
\hline & OR & $95 \% \mathrm{CLs}$ & HR & $95 \% \mathrm{CLs}$ \\
\hline Male gender & 0.90 & $0.66 ; 1.23$ & 2.02 & $1.67 ; 2.44$ \\
\hline $\mathrm{BMI}<20$ & 1.06 & $0.45 ; 2.50$ & 1.32 & $0.90 ; 1.96$ \\
\hline $\mathrm{BMI}>30$ & 0.92 & $0.56 ; 1.51$ & 0.94 & $0.72 ; 1.24$ \\
\hline High waist circumference & 0.80 & $0.54 ; 1.18$ & 1.29 & $1.04 ; 1.60$ \\
\hline Low physical activity at 70 & 0.42 & $0.25 ; 0.71$ & 1.29 & $1.04 ; 1.59$ \\
\hline Married at age 70 & 1.47 & $1.07 ; 2.01$ & 0.78 & $0.66 ; 0.93$ \\
\hline Smoker/stopped $<10$ years ago & 1.07 & $0.77 ; 1.47$ & 1.37 & $1.14 ; 1.64$ \\
\hline School education above basic & 1.38 & $1.02 ; 1.86$ & 0.91 & $0.75 ; 1.11$ \\
\hline Birth cohort & 1.03 & $1.01 ; 1.04$ & 0.97 & $0.97 ; 0.98$ \\
\hline
\end{tabular}

more recent birth cohorts (OR 0 1.03, 95\% CI: $1.01 ; 1.04)$.

Table 7 also shows the association of the potential confounders included in the final model with total mortality. As expected, there is a positive association between the risk of mortality and male gender $(\mathrm{HR}=$ 2.02, 95\% CI: $1.67 ; 2.44)$, high waist circumference $(\mathrm{HR}=1.29,95 \% \mathrm{CI}: 1.04 ; 1.60)$, low level of physical activity $(\mathrm{HR}=1.29,95 \% \mathrm{CI}: 1.04 ; 1.59)$ and smoking $(\mathrm{HR}=1.37,95 \% \mathrm{CI}: 1.14 ; 1.64)$. Inverse associations were found for marital status $(\mathrm{HR}=0.78,95 \% \mathrm{CI}$ : $0.66 ; 0.93)$, and for birth cohort, which we considered as a proxy for age/period effects $(\mathrm{HR}=0.98,95 \% \mathrm{CI}$ : $0.97 ; 0.98)$. Finally, BMI did not show any significant association.

\section{Discussion}

In this paper, we investigated the association of a dietary pattern close to the Mediterranean diet with total mortality in population-based cohorts of 70-yearold Swedes. Although we did not find an association when testing the previously defined HALE mMDS on our Swedish population (Knoops et al. 2004), we were able to refine this score in order to obtain one that best described strict adherence to a Mediterranean diet-like pattern. None of the items included in the score were found to be essential for the association with the total score. Finally, the association was not attenuated when adjusting for ADL, thus showing that the protection by the Mediterranean pattern was not limited to those subjects still living independently at the time of the dietary assessment, or biased in some way by how impaired they were at enrolment. Furthermore, the effect was only slightly attenuated when adjusting for several indicators of cardiovascular risk, suggesting that the protective effect was not limited to high-risk subjects.

Other studies had already found a positive association of Mediterranean diet and health (Lagiou et al. 2006; Knoops et al. 2004; Trichopoulou et al. 1995), showing the effects of increasing the intake of vegetables and fruit, fish, and cereals, while decreasing animal products such as dairy and meat. In our study, we started by reproducing the same mMDS that was previously created by the HALE working group for their paper on Mediterranean diet and total mortality (Knoops et al. 2004) and did not find a significant trend, even when testing the association at the highest levels. However, we found an inverse association with total mortality when a refined version of the mMDS was tested instead of the original score. The association was indeed strong and robust after calculating the score considering wholegrain cereals instead of total cereals, adding alcohol (or red wine) intake, considering egg intake together with meat products and calculating the fat ratio including PUFA and not only MUFA in the numerator. The addition of alcohol intake should not be considered problematic, since the intakes in this population were not high (75th percentile: $7.6 \mathrm{~g}$ /day, 90th percentile: $16.3 \mathrm{~g} /$ day) and can then be considered in an order of magnitude quite close to international recommendations. Interestingly, beneficial effects of moderate alcohol intake have been recently confirmed in a study with a follow up of 
20 years that also considered many confounders typically associated with abstaining (such as past history of heavy drinking behavior, Holahan et al. 2010). Furthermore, our association was also confirmed when including red wine instead of alcohol, confirming that the positive result characterizes the subjects adhering to the healthiest diet patterns.

The possible explanation of the necessity of improving an existing score that had already worked in previous studies to find a robust association in the Swedish elderly may be due to the obvious differences between the original Mediterranean diet and the Swedish Mediterranean-like diet. This is particularly important in our population, since many subjects were born at the beginning of last century, when many products that were common in Southern Europe were not consumed in large quantities in the north. Swedish food habits have indeed undergone major changes in the last 30 years, particularly in relation to consumptions of fresh fruit and vegetables (now available in quantity even on the Scandinavian market) and cereals as well as a higher unsaturated fat proportion (Eiben et al. 2004). Another reasonable example is represented by MUFA sources, mainly olive oil in Southern European countries, mostly margarines (a source of trans fatty acids, especially at the time they were measured) in the oldest birth cohorts and only marginally derived from olive oil in the 1930 birth cohort.

However, by applying stricter rules, such as substituting wholegrain cereals instead of total cereals (often characterized by a higher sugar content than in South Europe), including PUFA intake (in Sweden, fish is an important contributor), adding alcohol (and also red wine only), and including egg intake (a probable indicator of a low-quality diet), we found a protective pattern in our Swedish population.

Another important issue is that single food groups were not always found to be inversely or directly associated with the mortality risk, although the full score is robust to exclusions of any single component. This suggests that the use of this and similar scores in nutritional epidemiology studies is indeed a useful strategy for investigating associations between diet and health outcomes.

Our study has both strengths and limitations, the former being the high quality of nutritional data obtained by a validated diet history during a face to face interview with the dietician (confirmed by the high EI/BMR ratio and by concordance of our estimated intakes with National Surveys; Becker 1994), the possibility of adjusting for different known confounders and the availability of weight and waist circumference measurements both at baseline and at follow up. The limitations include the lack of repeated dietary assessment and the small size of the study population. Moreover, it must be acknowledged that diet patterns alone may inherently co-vary with other health-related phenomena (e.g., healthy lifestyles, illnesses, weight status). Thus, it is important to note that associations were independent of cardiovascular risk factors, weight and waist circumference change, SES, education, ADL, and other risk factors. Moreover, it is worth mentioning that although the analyses were always adjusted for birth cohort, the results could still be influenced by a residual cohort effect as suggested by the fact that the protective effect of the Mediterranean diet pattern was stronger in the youngest cohorts. This was probably due to a higher quality of nutritional data (or higher health consciousness in the subjects) in the most recent surveys.

From the above mentioned results, it clearly emerges that it would be useful to put more emphasis on dietary recommendations directed to the elderly in order to encourage increased consumption of fruit and vegetables, wholegrain cereals and fish, while reducing the intake of dairy and meat products, in favor of other healthier protein sources such as legumes. This is particularly important in Sweden, considering that current guidelines do not always place sufficient emphasis on this type of recommendation. For instance, although our results are quite in line with Nordic Nutrition Recommendations (Nordic Council of Ministers 2004), the present Swedish Nutrition Recommendations Objectified (Barbieri and Lindvall 2005), is in some ways different from Mediterranean diet-based features. Indeed, the former considers acceptable a daily intake of $500 \mathrm{ml}$ milk (in addition to other dairy products) and suggests some equilibrated menus that do not consider olive oil either as a condiment or as a cooking fat, while including margarine on a daily basis. Moreover, it often refers to "refined rye bread" and "white bread" instead of suggesting wholegrain products, and includes meat products in two meals per day. At the same time, it is also worth mentioning that carbohydrate restriction is becoming an increasingly popular (although not scientifically based) weight control method in the population, a modification which is also not supported, vis-à- 
vis mortality, in our nutrient-level analyses simulating carbohydrate replacement.

Overall, studies of dietary patterns are inherently complex. However, regardless of scientific approach, there is a remarkable convergence of evidence on the fact that dietary patterns associated with longevity emphasize fruits and vegetables and are reduced in saturated fat, meats, refined grains, sweets, and fullfat dairy products (Appel 2008). This is not only the case for the Mediterranean diet pattern, but also for other pattern such as the DASH diet (Parikh et al. 2009) or the Okinawa diet (Willcox et al. 2009).

\section{Conclusions}

To conclude, we can reasonably state that the adherence to a Mediterranean-like dietary pattern is inversely related to total mortality also in a Swedish population of elderly subjects. Our hope is that the results of the present research will stimulate a productive discussion on these issues and be considered in updated food- and nutrient-level guidelines for the population.

Acknowledgment The authors' responsibilities were as follows-GT performed the data analysis and wrote the manuscript; LL coordinated the research, contributed to the interpretation of results and to the writing of the manuscript; ER and GE provided support for the correct application of nutritional data, helped with the interpretation of results and gave critical comments on the manuscript; AW contributed to the interpretation of results and gave critical comments on the manuscript; VS provided statistical expertise and gave critical comments on the manuscript. The research was funded by the Swedish Council on Working Life and Social Research (FAS) EpiLife centre.

Financial disclosures All authors have no financial disclosures.

\section{Conflict of interest None declared.}

Disclaimer The views expressed are those of the authors and should not be construed to represent the positions of anybody else.

Open Access This article is distributed under the terms of the Creative Commons Attribution Noncommercial License which permits any noncommercial use, distribution, and reproduction in any medium, provided the original author(s) and source are credited.

\section{References}

Appel LJ (2008) Dietary patterns and longevity. Circulation 118:214-215

Barbieri HE, Lindvall C (2005) De svenska näringsrekommendationerna översatta till livsmedel: underlag till generella råd på livsmedels-och måltidsnivå för friska vuxna Swedish Nutrition Recommendations Objectified (SNO). Basis for general advice on food consumption for healthy adults. Livsmedelsverkets rapport n. 20/2005. http://www. slv.se/upload/dokument/rapporter/mat_naring/ Report_20_2005_SNO_eng.pdf

Becker BW (1994) Dietary habits and nutrient intake in Sweden 1989. Statens livsmedelsverk, Uppsala, $240 \mathrm{pp}$

Bengtsson C, Ahlqvist M, Andersson K, Björkelund C, Lissner L, Söderström M (1997) The prospective population study of women in Gothenburg, Sweden, 1968-69 to 1992-93. A 24-year follow-up study with special reference to participation, representativeness, and mortality. Scand J Prim Health Care 15:214-219

Chrysohoou C, Panagiotakos DB, Aggelopoulos P, Kastorini CM, Kehagia I, Pitsavos C, Stefanadis C (2010) The Mediterranean diet contributes to the preservation of left ventricular systolic function and to the long-term favorable prognosis of patients who have had an acute coronary event. Am J Clin Nutr 92:47-54

De Lorgeril M, Renaud S, Mamelle N, Salen P, Martin JL, Monjaud I, Guidollet J, Touboul P, Delaye J (1994) Mediterranean alpha-linolenic acid-rich diet in secondary prevention of coronary heart disease. Lancet 343:1454-1459

de Lorgeril M, Salen P, Martin JL, Monjaud I, Delaye J, Mamelle N (1999) Mediterranean diet, traditional risk factors, and the rate of cardiovascular complications after myocardial infarction: final report of the Lyon Diet Heart Study. Circulation 99:779-785

Department of Health (1991) Report on health and social subjects; 41. Dietary reference values for food energy and nutrients for the United Kingdom. HMSO, London

Eiben G, Andersson CS, Rothenberg E, Sundh V, Steen B, Lissner L (2004) Secular trends in diet among elderly Swedes-cohort comparisons over three decades. Public Health Nutr 7:637-644

Eiben G, Dey DK, Rothenberg E, Steen B, Björkelund C, Bengtsson C, Lissner L (2005) Obesity in 70-year-old Swedes: secular changes over 30 years. Int J Obes (Lond) 29:810-817

Flight I, Clifton P (2006) Cereal grains and legumes in the prevention of coronary heart disease and stroke: a review of the literature. Eur J Clin Nutr 60:1145-1159

Haveman-Nies A, de Groot L, van Staveren W (2003) Relation of dietary quality, physical activity, and smoking habits to 10 -year changes in health status in older Europeans in the SENECA study. Am J Public Health 93:318-323

Huijbregts P, Feskens E, Rasanen L, Fidanza F, Nissinen A, Menotti A, Kromhout D (1997) Dietary pattern and 20 year mortality in elderly men in Finland, Italy, and the Netherlands: longitudinal cohort study. BMJ 315:13-17

Keys AB (1980) Seven countries: a multivariate analysis of death and coronary heart diseases. Harvard University Press, Cambridge 
Knoops KT, de Groot LC, Kromhout D, Perrin AE, MoreirasVarela O, Menotti A, van Staveren WA (2004) Mediterranean diet, lifestyle factors, and 10-year mortality in elderly European men and women: the HALE project. JAMA 292:1433-1439

Holahan CJ, Schutte KK, Brennan PL, Holahan CK, Moos BS, Moos RH (2010) Late-life alcohol consumption and 20-year mortality. Alcohol Clin Exp Res 34:1-11

Lagiou P, Trichopoulou D, Sandin S, Lagiou A, Mucci L, Wolk A, Weiderpass E, Adami HO (2006) Mediterranean dietary pattern and mortality among young women: a cohort study in Sweden. Brit J Nutr 96:384-392

Lissner L, Skoog I, Andersson K, Beckman N, Sundh V, Waern M, Zylberstein DE, Bengtsson C, Björkelund C (2003) Participation bias in longitudional studies-experiences from the The Population Study of women in Gothenburg. Scand J Prim Health Care 21:242-247

Mai V, Kant AK, Flood A, Lacey JV Jr, Schairer C, Schatzkin A (2005) Diet quality and subsequent cancer incidence and mortality in a prospective cohort of women. Int J Epid 34:54-60

Mukamal KJ, Chen CM, Rao SR, Breslow RA (2010) Alcohol consumption and cardiovascular mortality among US adults, 1987 to 2002. J Am Coll Cardiol 55:1328-1335

Nordic Council of Ministers (2004) Nordic Nutrition Recommendations 2004. Integrating nutrition and physical activity. Norden, Copenhagen

Parikh A, Lipsitz SR, Natarajan S (2009) Association between a DASH-like diet and mortality in adults with hypertension: findings from a population-based follow-up study. Am J Hypertens 22:409-416

Rothenberg E, Bosaeus I, Steen B (1996) Food habits in three 70 -year-old free-living populations in Gothenburg, Sweden. A 22-year cohort study. Scand J Nutr 40:104-110
Rothenberg E, Bosaeus I, Steen B (1997) Evaluation of energy intake estimated by a diet history in three free-living 70 year old populations in Gothenburg, Sweden. Eur J Clin Nutr 51:60-66

Rothenberg E, Bosaeus I, Lernfelt B, Landahl S, Steen B (1998) Energy intake and expenditure: validation of a diet history by heart rate monitoring, activity diary and doubly labeled water. Eur J Clin Nutr 52:832-838

Seymour J, Calle E, Flagg E, Coates R, Ford E, Thun M (2003) Diet quality index as a predictor of short-term mortality in the American Cancer Society Cancer Prevention Study II Nutrition Cohort. Am J Epidem 157:980-988

Sonn U, Asberg KH (1991) Assessment of activities of daily living in the elderly. A study of a population of 76-yearolds in Gothenburg, Sweden. Scand J Rehabil Med 23:193-202

Trichopoulou A, Kouris-Blazos A, Wahlqvist ML, Gnardellis C, Lagiou P, Polychronopoulos E, Vassilakou T, Lipworth L, Trichopoulos D (1995) Diet and overall survival in elderly people. BMJ 311:1457-1460

Trichopoulou A, Orfanos P, Norat T, Bueno-de-Mesquita B, Ocke MC, Peeters PH et al (2005) Modified Mediterranean diet and survival: the EPIC-Elderly study. BMJ 330:991

Willcox DC, Willcox BJ, Todoriki H, Suzuki M (2009) The Okinawan diet: health implications of a low-calorie, nutrient-dense, antioxidant-rich dietary pattern low in glycemic load. J Am Coll Nutrition 28:500S-516S

Willett WC (1998) Nutritional epidemiology, 2nd edn. Oxford University Press, New York

Willett WC, Sacks F, Trichopoulou A, Drescher G, Ferro-Luzzi A, Helsing E, Trichopoulos D (1995) Mediterranean diet pyramid: a cultural model for healthy eating. Am J Clin Nutr 61:1402S-1406S 